\title{
Sustaining Transparency in Government Information and the (r)evolution of Cloud Computing
}

\begin{abstract}
A.J. Million, M.A.
University of Missouri, School of Information Science \& Learning Technologies.

111 London Hall, Columbia, MO 65211 USA. E-mail: ajmillion@gmail.com

Terry Weech, Ph.D.

University of Illinois at Urbana-Champaign, Graduate School of Library \& Information Science. 501 E. Daniel St., Champaign, IL 61820 USA. E-mail: weech@,illinois.edu

Abstract: Libraries play an important role in ensuring access to government information. Prior to the digital age, libraries provided on-site access to government information using print and print facsimile sources (e.g. microfiche and CD-ROM disks). The emergence of distributed computing models, however, has led many government resources to move online, thus challenging libraries' capacity to serve as civic information providers. Moving from a geographically dispersed group of analog sources to a centralized collection in the cloud introduces the potential for restriction and revision, especially with regard to official records of policy and actions. This paper explores the characteristics of cloud computing that undermine libraries' ability to sustain free access to government information. We propose that libraries, and their advocates, should engage with governments and their information providers to craft legally-binding agreements that establish protections which facilitate sustainability. Cloud computing may undermine libraries' ability to guarantee government information access, but it does not necessarally impugn their capacity to serve patrons and the public interest.
\end{abstract}

Keywords: Cloud Computing, E-Government, Information Access, Sustainability

\section{Introduction}

In their Statement on Libraries and Sustainable Development, the International Federation of Library Associations and Institutions (IFLA) asserts that all humans have the right to live in an environment that is adequate for their wellbeing. To this end, IFLA has recognized that governments must help citizens meet their present needs without compromising future needs. Libraries, the argument goes, help to "promote sustainable development by ensuring the freedom of access to information" (IFLA, 2013); however, this capacity is largely dependent on the capacity of libraries to sustain access to government information. Prior to the digital age, libraries were able to sustain access to government information by obtaining and storing print or print facsimile resources in physical collections. Today, alternately, most libraries operate in an environment where e-government and cloud computing - despite their benefits - challenge libraries with many new issues. This paper aims to stimulate a discussion of government information sustainability strategies that pertain to libraries, cloud computing, and information access.

Increasingly, as governments rely on digital tools to store and disseminate information, the relative importance of online access to information grows. Seeking to spark a discussion about cloud computing, this paper asks two informal questions: (1) What are the most effective strategies for sustaining access to government information in libraries? Also, (2) How does technology, especially cloud computing, impact the ability of libraries and information professionals to ensure free, open access to government information? To answer these questions, we present a brief history of the role of libraries in ensuring access to civic information with an emphasis on the United States (U.S.) and, to a lesser extent, other democratic nations. Next, we provide an overview of cloud computing and offer case studies that identify the challenges associated with cloud-based service models. We also examine the extent to which the strengths of cloud computing, notably its flexibility and low cost, justify concerns about its limitations. As a 
solution, we argue that libraries, and their advocates, should petition government information providers to shape third-party service-level agreements (SLA) in a way that protects library and patron interests. If commercial providers are not utilized, libraries and their advocates should instead work with governments to craft analogous legal agreements.

\section{History}

In the U.S., libraries often provide access to federal, state, and local government information. Its founders acknowledged the importance of records depositories and cited barriers to access as a grievance against the British Crown in their Declaration of Independence. Many depository collections formed during the $19^{\text {th }}$ century, and the American Library Association's (ALA) Government Documents Roundtable (GODORT) was established in the $20^{\text {th }}$ century. During the mid- $20^{\text {th }}$ century, the issue of free government information access was taken up by social justice advocates. Implicit within the ALA Documents Roundtable slogan "documents to the people" was their professional insistence that the objective of providing free access to government information is public accountability. To promote accountability, the U.S. has adopted two different dissemination strategies: (1) exempting government information from copyright law and (2) creating the modern Federal Depository Library Program (FDLP).

While there are many countries in the world, looking to the U.S. allows us to highlight an objective that all democratic governments share: citizens in all democracies require and expect sustainable access to government information. Effective self-government requires having access to information about one's own government, so we believe that looking at the U.S. helps to frame the historical context in which cloud computing and libraries must be considered.

The U.S. is one of the few countries in the world that exempts government documents from copyright law to ensure that it can be freely disseminated. In regards to dissemination, the FDLP dispenses physical records to more than 1,400 libraries. These libraries, in turn, accept responsibility for providing physical access as well as preserving government material. From a copyright perspective, librarians in the U.S. are also committed to providing access to government information. While federal material is technically federal property, because these resources are exempt from copyright law, libraries often allow citizens to reproduce them at will. The result is that information access - at least historically - has remained sustainable and generally unable to be manipulated.

Still, in recent years, many U.S. librarians have become increasingly concerned with their ability to sustain access to government information. During the $20^{\text {th }}$ century, storage and preservation were two prevailing concerns. Libraries utilized microform, microfiche, and micro-cards as alternative formats to save space. Then, as digital information systems expanded, depository libraries began to use CD-ROM discs. Finally, the emergence and commercialization of the Internet brought forth further changes as Web-based media came to be not only used but demanded by users. Although there are many benefits associated with the Internet, librarians have understandably recognized the challenges that are associated with moving material to the cloud. As we will show later, this arguably creates challenges for those committed to ensuring sustainable government information access.

\section{Cloud Computing and Sustainability}

The term "cloud computing" entails several generalizable characteristics. To determine the impact of cloud computing on libraries, as well as the ability of libraries to sustain access to 
government information, we must identify these characteristics. "Although computer scientists [...] may have a strict definition of cloud computing involving 'on-demand network access to a shared pool of configurable computing resources', [...] it's enough to think about cloud computing as library data and services hosted beyond the library's walls and accessible via the web" (Corrado \& Moulaison, 2012). For the purposes of this paper, we opt to sidestep definitions like those offered by technical or international authorities.

In recent years, cloud computing has grown due to the flexibility of its associated service models; software as a service (SaaS), platform as a service (PaaS), and infrastructure as a service (IaaS). Rather than requiring information providers to maintain an in-house operation, cloud computing outsources technical operations to leverage external expertise and take advantage of economies of scale. Worded another way, cloud computing increases flexibility and cost-efficiency because it capitalizes on the division of labor and resources. This explains why government agencies often rely on cloud computing to host and disseminate information. Adopting a cloud-based approach to store and disseminate information means that government information providers usually provide better service than they could otherwise on their own.

Despite the potential for reduced costs, and increased flexibility, cloud computing also comes with associated costs. Information providers must rely on either public or private third-party technicians to maintain their digital infrastructure. By relying on these third-parties, government agencies consequentially accept that a high degree of purchaser control will frequently result in lower economies of scale, and thus higher costs. Larger economies of scale, on the other hand, force purchasers to forfeit direct control over their data and/or services (Lopes, 2009). While this is not an issue per se, surrendering control of digital government assets may create an environment in which public access is curtailed.

By this point, it goes without saying that government agencies should carefully weigh the pros and cons of cloud computing. What happens if a vendor goes out of business or if bills aren't paid on time? What about natural disasters? Does a server's uptime, response time, and software maintenance schedule influence accessibility? How secure is a server and can official records be manipulated? All of these questions raise important concerns that are typically addressed in a service-level agreement or internal memorandum of understanding with agencies or commercial providers (Patel, Ranabahu, \& Sheth, 2009). Yet, these agreements are rarely spoken of by the library community despite the fact that they represent a formal means by which to protect the interests of libraries and their patrons.

\section{Case Studies}

Numerous examples of online government information resources exist. To examine the implications of relying on cloud-based computing models we will now look at two examples. The first example is Recovery.gov. Recovery.gov was created in response to the passage of a U.S. economic stimulus bill following the 2008 global financial crisis. Presently, the site offers detailed information about how $\$ 811$ billion dollars was spent on projects ranging from roads to medical research. While stimulus spending is not new, providing online information to the public about its scale and scope is. Alice Siempelkamp, assistant director of Recovery.gov, notes that the transparency efforts associated with the website were among "the most high profile federal efforts [ever...] probably in history" (personal communication, January 30, 2013). Yet, because the site was built using emergency funding, it is unknown how long Recovery.gov will remain live. In 2012, the Board governing the site was extended by two years. Additionally, legislation continues to come and go which, according to Siempelkamp, "would create a permanent Board to 
continue [Recovery.gov's] mission in the long term [and...] would oversee all government spending" (personal communication, March 27, 2013). Yet, in part because Recovery.gov was built using external contractors, and because it operates using discretionary funding, there is no guarantee that it will remain online or accessible.

Another quasi-government resource is the Transportation International Research Documentation (TRID) database. The product of a merger between the Transportation Research Information Services (TRIS) database and International Transport Research Documentation (ITRD) database, this research tool is arguably the largest source of transportation research in the world. More importantly, because of the nature of transportation as an economic sector, it is funded primarily by national (and local) governments and non-profit organizations. With roots dating to the 1960s TRID is presently housed within the U.S. National Academy of Sciences. According to its manager, Lisa Loyo, it is also maintained by an in-house crew where they are able to keep tabs on both their server and the database's content (personal communication, November 30, 2013). To accommodate community needs, however, the database is also served by a committee of the Transportation Research Board (TRB) which provides input into matters regarding long-term sustainability. While library patrons have no direct say in operational activity and legal agreements with user groups are not in place, the advisory committee mitigates some of the concerns about cloud computing that we have presented.

\section{Problems and Solutions}

Based on our exploration, there is evidence that cloud computing provides a means by which government agencies can offer effective, useful services. Cloud computing is associated with limitations, but the cloud itself is "neither inherently insecure nor secure" (Chaput \& Ringwood, 2010, p. 241). At the same time, however, the underlying economic structure of cloud computing does implicitly reduce agency control to drive down costs. This, in turn, allows for service interruptions and the potential for content revision if steps are not taken to prevent them. Speaking about the later, it has been noted that "internal computer fraud is a more significant threat than external hacking" (Iowa State University, 2009).

Despite these threats, there are means by which the library community can protect itself and its patrons, notably by establishing or shaping the service agreements mentioned earlier. Precisely because distributed computing models rely on third-parties, government information providers often fashion legal agreements to protect their interests, and libraries can benefit from participating. Indeed, if citizens are to engage in the democratic process using libraries as any sort of access point or partner, then there is reason to believe that libraries and their advocacy groups should petition government information providers to take stakeholder needs into account.

As a service model, cloud computing is relatively new, and it is arguable that public policy is still in the process of adjusting to it (Jaeger, Lin, \& Grimes, 2009). Based on our understanding of its structure, as well as the case studies we have provided, there is a need for libraries to act accordingly. While libraries and their advocates do not represent all information seekers, they still represent large bodies of them and libraries can take steps to ensure that public information remains sustainable. As a result, we conclude that libraries should try to gain a voice in the creation and maintenance of cloud-based government information resources, rather than viewing them as the sole responsibility of others. Conversely, governments should consider the importance of the information that they offer and should take care to guarantee that the costs of adopting a cloud computing model does not outweigh the associated benefits. 


\section{Conclusion}

In summary, libraries face very real questions about how they can provide sustainable access to government information in an era where cloud computing dominates. Perhaps these questions can be answered in a print-based world; however, because patrons generally prefer digital access, there is arguably no going back. The question to ask, then, is how can libraries promote access to government information despite shifting technology? Based on the characteristics of cloud computing, we believe that the answer to this is through networking, cooperation, and the legal system. Technology does impact the ability of libraries and information professionals to deliver free, open access to government information. At the same time, a reliance on this technology also necessitates the utilization of legal agreements between government information providers and third parties. To ensure public information remains sustainable information, libraries and library advocates should take full advantage of this existing need to create collaborative agreements and shape them in a positive way.

\section{Acknowledgements}

We would like to thank Dr. Heather L. Moulaison for introducing the authors.

\section{References}

Chaput, S., \& Ringwood, K. (2010). Cloud compliance: A framework for using cloud computing in a regulated world. In Antonpolos, N., \& Gillam, L. (Eds.) Cloud computing: Principles, Systems and Applications. London: Springer-Verlag.

Corrado, E., \& Moulaison, H. (2012, March 5). The library cloud pros and cons. Library Journal. Retrieved from http://www.thedigitalshift.com/2012/03/software/the-library-cloud-pros-and$\underline{\text { cons }}$

IFLA (International Federation of Library Associations and Institutions). (2013, March 27). Statement on libraries and sustainable development. Retrieved from http://www.ifla.org/publications/statement-on-libraries-and-sustainable-development

Jaeger, P., Lin, J., \& Grimes, J. (2009). Where is the cloud? Geography, economics, environment, and jurisdiction in cloud computing. First Monday, 14(4-5). Retrieved from http://firstmonday.org/ojs/index.php/fm/article/view/2456/2171

Iowa State University. (2009, July 31). Iowa State researcher says internal security breaches pose bigger threat than hackers. Retrieved from http://archive.news.iastate.edu/news/2009/jul/security

Lopes, P. (2009). Cloud computing and digital libraries: First perspectives on a future technological alliance. Informally published manuscript, Aveiro University, Retrieved from http://issuu.com/pedrolopes/docs/cloudcomputing_digitallibraries

Patel, P., Ranabahu, A., \& Sheth, A. (2009). Service level agreement in cloud computing. Informally published manuscript, Wright State University, Retrieved from http://corescholar.libraries.wright.edu/knoesis/78 